\title{
Subclinical myocardial dysfunction and dyssynchrony after Ross or Ross-Konno procedure
}

\author{
Katherine Ellenberger $^{1,2}$, Kazuaki Negishi ${ }^{1,2}$ \\ ${ }^{1}$ Department of Cardiology, Nepean Hospital, New South Wales, Australia; ${ }^{2}$ Sydney Medical School Nepean, Faculty of Medicine and Health, \\ Charles Perkins Centre Nepean, The University of Sydney, New South Wales, Australia \\ Correspondence to: Professor. Kazuaki Negishi, MD, PhD, FACC, FESC, FASE, FAHA. The University of Sydney, Nepean Clinical School, Level 5, \\ South Block, PO Box 63 Penrith NSW 2751, USA. Email: Kazuaki.Negishi@sydney.edu.au. \\ Provenance and Peer Review: This is an invited article commissioned and reviewed by the Section Editor Xicheng Deng (Department of Cardiothoracic \\ Surgery, Hunan Children's Hospital, Changsha, Hunan, China). \\ Comment on: Schäfer M, Browne LP, von Alvensleben JC, et al. Ventricular interactions and electromechanical dyssynchrony after Ross and Ross- \\ Konno operations. J Thorac Cardiovasc Surg 2019;158:509-17.
}

Submitted Jan 19, 2020. Accepted for publication Mar 12, 2020.

doi: $10.21037 /$ tp.2020.03.11

View this article at: http://dx.doi.org/10.21037/tp.2020.03.11

Over recent decades advances in the management of congenital heart disease (CHD) have led to increased survival and subsequently doubled the prevalence of CHD in the paediatric population (1). Despite these advances, chronic heart failure is a leading cause of death in adult CHD patients $(2,3)$. More than half a century has passed since the inception of the Ross procedure (4) and, as its predominantly paediatric population ages, a clear understanding of their subsequent cardiac remodelling has become increasingly relevant. Since Donald Ross performed the first aortic valve replacement with a pulmonary autograft, the procedure has remained an interesting option for aortic valve replacement. The primary population remains children and adolescents, as the pulmonary graft expands to allow for somatic growth. Whilst the number of Ross procedures had declined over time, recent analyses of long-term outcomes have suggested decreased cardiac and valve related mortality, and increased freedom from stroke and major bleeding $(5,6)$, compared to mechanical aortic valve replacements. However, the procedure is more challenging than a standard aortic valve replacement, and concerns regarding the potential for late dysfunction of the semilunar valve have limited its uptake to a select group of centres worldwide. In 1975 the Ross procedure was first combined with the Konno aortoventriculoplasty (i.e., RossKonno procedure), allowing for the treatment of congenital aortic stenosis with associated sub-aortic membranes or multilevel left ventricular outflow tract stenosis (7). However, the manipulation of the interventricular septum and the mobilization and reimplantation of the coronary arteries has inherent risks of damage to the septal myocardium and conduction system, leading to the development of ventricular dyssynchrony.

The assessment of myocardial deformation, or "myocardial strain", has become increasingly popular to more accurately estimate not only myocardial function but also mechanical ventricular dyssynchrony; the time to peak deformation allows a quantifiable way to assess the temporal variance of contraction across myocardial regions. Additionally, the widespread use of strain imaging to detect subclinical left ventricular (LV) dysfunction has been utilised across a range of both congenital and adult noncongenital cardiology populations $(8,9)$.

Whilst several studies have addressed myocardial strain and the relationship between mechanical and electrical dyssynchrony in CHD patients (9-12), few have done so in the vulnerable population of Ross and Ross-Konno procedure patients. Recently, Schafer et al. evaluated the mechanical and functional biventricular performance using cardiac MRI in children and young adults who underwent a Ross ( $n=16)$ or Ross-Konno $(n=13)$ operation about 10 years prior and compared them with healthy controls with no known cardiovascular disease (13). They also assessed the degree of interventricular and intraventricular 
mechanical dyssynchrony and investigated whether ventricular mechanical indices are associated with electrical dyssynchrony when two groups are combined.

Their findings were 5-fold. (I) Ross-Konno group had significantly higher incidence of electrical dyssynchrony (defined by a QRS duration $\mathrm{z} \geq 2$ for both adult and paediatric populations) compared with the Ross group (85\% vs. $38 \%, \mathrm{P}=0.010)$ as would be anticipated with greater instrumentation of the septum and significantly longer QRS interval ( $126 \pm 22$ vs. $104 \pm 17 \mathrm{~ms}, \mathrm{P}<0.001)$; (II) no intergroup differences in $L V$ volumes were observed, yet patients in Ross and Ross-Konno groups had slightly lower ejection fraction than the control group but still being within normal range; (III) although global circumferential strain was similar among the three groups, global longitudinal strain was lower in Ross and Ross-Konno groups than the control group; (IV) the Ross-Konno group had significantly higher intraventricular mechanical dyssynchrony when compared with Ross and control groups, especially in the septum; (V) a linear relationship between QRS duration and LV mechanical dyssynchrony was demonstrated when Ross and Ross-Konno groups were combined $(\mathrm{R}=0.72 ; \mathrm{P}<0.001)$.

This study is very important for the following reasons. Although much focus has been on autograft function after Ross and Ross-Konno procedures, this research provides us with a greater understanding of cardiac remodelling affecting this population. As these patients reach middle and old age the prevalence of heart failure from conventional causes will increase; their abnormal biomechanics place them in the vulnerable position of having dyssynchronous contraction at baseline. In line, this study explicitly demonstrated reduced systolic function with increased mechanical dyssynchrony in a unique population with CMR-based deformation analysis (14). This opens up the potential effective treatment option, cardiac resynchronization therapy (CRT) in this population as well. Recent research has demonstrated that CMR end systolic septal strain, independent of QRS duration or morphology, is predictive of a response to CRT, defined as improvement in LV end systolic volume (15). Additionally, the use of CMR to further delineate the pattern of ventricular wall motion, and placement of the LV lead concordant with the least contracting LV segment, independently predicts echocardiographic response to CRT (16). This is a promising area of research in both the congenital and noncongenital heart failure population.

Whilst CRT is a well-established treatment in the adult heart failure population, evidence in the paediatric and congenital population is scarce. The challenge is to identify the patients who will obtain the greatest benefit from CRT because few paediatric patients fit Class I indications for CRT [NYHA Class III or IV symptoms, despite optimal medical therapy, with LVEF $\leq 35 \%$ and QRS duration $>120$ $\mathrm{ms}$ (17)]. Most patients enrolled in paediatric CRT trials are NYHA Class I or II, with concomitant indications for surgery that have prompted CRT implantation (18-20). Using the QRS duration is an imperfect tool for identifying dyssynchrony; the cut off of a QRS duration of $163 \mathrm{~ms}$ yields a sensitivity and specificity of only $53 \%$ to predict a clinical response in adult heart failure patients (21). Unfortunately, none had QRS $>160 \mathrm{~ms}$ in the population, although a linear relationship between QRS duration and LV mechanical dyssynchrony suggests QRS can be a reasonable surrogate marker. Furthermore multiple studies in the paediatric cardiomyopathy population have shown that mechanical dyssynchrony is often present in the absence of electrical dyssynchrony, with no correlation between QRS duration and interventricular or intraventricular dyssynchrony $(10,11)$.

The authors should be congratulated on their completion of comprehensive and detailed assessment on deformation and dyssynchrony in these unique populations. Nevertheless, the study has some limitations. The small sample size $(n=29)$ may limit the generalisability of these findings, however future studies may benefit from including multiple centres with larger recruitment possibilities. Additionally, this is a cross sectional study, and as such provides us with only a snapshot of the current cardiac biomechanics, with no data on potential progression of dyssynchrony or LV dysfunction. Extrapolation of how these findings may impact future outcomes, should be made with caution as further longitudinal follow up is required to better inform clinical decision making.

Whilst the findings of Shafer $e t$ al. are exciting, there are several steps prior to its clinical implementation. First, it remains unclear what the finding of abnormal strain means for this population. Although this research demonstrated they have reduced myocardial strain, Ross and Ross Konno procedures have good long term results with a low incidence of heart failure (22). Numerous studies have demonstrated abnormal strain in a range of CHD populations, including ventricular septal defects (23), tetralogy of Fallot (12), and transposition of the great arteries (24), however the clinical significance of these findings is not always clear. In a heterogeneous adult population reduced GLS is an independent prognostic predictor of major adverse cardiac 
events, stronger even than LVEF (8), however whether this remains true in the Ross and Ross-Konno groups is yet to be explored. Further researches are warranted.

\section{Acknowledgments}

Funding: KN reports grants from National Heart Foundation of Australia, outside the submitted work.

\section{Footnote}

Conflicts of Interest: All authors have completed the ICMJE uniform disclosure form (available at http://dx.doi. org/10.21037/tp.2020.03.11). The authors have no conflicts of interest to declare.

Ethical Statement: The authors are accountable for all aspects of the work in ensuring that questions related to the accuracy or integrity of any part of the work are appropriately investigated and resolved.

Open Access Statement: This is an Open Access article distributed in accordance with the Creative Commons Attribution-NonCommercial-NoDerivs 4.0 International License (CC BY-NC-ND 4.0), which permits the noncommercial replication and distribution of the article with the strict proviso that no changes or edits are made and the original work is properly cited (including links to both the formal publication through the relevant DOI and the license). See: https://creativecommons.org/licenses/by-nc-nd/4.0/.

\section{References}

1. Marelli AJ, Mackie AS, Ionescu-Ittu R, et al. Congenital heart disease in the general population: Changing prevalence and age distribution. Circulation 2007;115:163-72.

2. Verheugt CL, Uiterwaal CSPM, Van Der Velde ET, et al. Mortality in adult congenital heart disease. Eur Heart J 2010;31:1220-9.

3. Oechslin EN, Harrison DA, Connelly MS, et al. Mode of death in adults with congenital heart disease. Am J Cardiol 2000;86:1111-6.

4. Ross DN. Surgical reconstruction of the aortic valve. Lancet 1963;1:571-4.

5. Mazine A, David TE, Rao V, et al. Long-Term Outcomes of the Ross Procedure Versus Mechanical Aortic Valve Replacement: Propensity-Matched Cohort Study.
Circulation 2016;134:576-85.

6. El-Hamamsy I, Bouhout I. The Ross procedure: time for a hard look at current practices and a reexamination of the guidelines. Ann Transl Med 2017;5:142.

7. Konno S, Imai $Y$, Iida $Y$, et al. A new method for prosthetic valve replacement in congenital aortic stenosis associated with hypoplasia of the aortic valve ring. J Thorac Cardiovasc Surg 1975;70:909-17.

8. Kalam K, Otahal P, Marwick TH. Prognostic implications of global LV dysfunction: A systematic review and metaanalysis of global longitudinal strain and ejection fraction. Heart 2014;100:1673-80.

9. Huntgeburth M, Germund I, Geerdink LM, et al. Emerging clinical applications of strain imaging and three-dimensional echocardiography for the assessment of ventricular function in adult congenital heart disease. Cardiovascular diagnosis and therapy 2019;9:S326-45.

10. Friedberg MK, Roche SL, Balasingam M, et al. Evaluation of Mechanical Dyssynchrony in Children With Idiopathic Dilated Cardiomyopathy and Associated Clinical Outcomes. Am J Cardiol 2008;101:1191-5.

11. Friedberg MK, Silverman NH, Dubin AM, et al. Mechanical Dyssynchrony in Children with Systolic Dysfunction Secondary to Cardiomyopathy: A Doppler Tissue and Vector Velocity Imaging Study. J Am Soc Echocardiogr 2007;20:756-63.

12. Jing L, Haggerty CM, Suever JD, et al. Patients with repaired tetralogy of Fallot suffer from intra-and interventricular cardiac dyssynchrony: A cardiacmagnetic resonance study. Eur Heart J Cardiovasc Imaging 2014;15:1333-43.

13. Schäfer M, Browne LP, von Alvensleben JC, et al. Ventricular interactions and electromechanical dyssynchrony after Ross and Ross-Konno operations. J Thorac Cardiovasc Surg 2019;158:509-17.

14. Vo HQ, Marwick TH, Negishi K. MRI-Derived Myocardial Strain Measures in Normal Subjects. JACC Cardiovasc Imaging 2018;11:196-205.

15. Zweerink A, van Everdingen WM, Nijveldt R, et al. Strain imaging to predict response to cardiac resynchronization therapy: a systematic comparison of strain parameters using multiple imaging techniques. ESC Heart Fail 2018;5:1130-40.

16. Hartlage GR, Suever JD, Clement-Guinaudeau S, et al. Prediction of response to cardiac resynchronization therapy using left ventricular pacing lead position and cardiovascular magnetic resonance derived wall motion patterns: A prospective cohort study. J Cardiovasc Magn 
Reson 2015;17:57.

17. ACC/AHA/HRS 2008 Guidelines for Device-Based Therapy of Cardiac Rhythm Abnormalities. A Report of the American College of Cardiology/American Heart Association Task Force on Practice Guidelines (Writing Committee to Revise the ACC/AHA/NASPE 2002 Guideline, (2008).

18. Dubin AM, Janousek J, Rhee E, et al. Resynchronization therapy in pediatric and congenital heart disease patients: An international multicenter study. J Am Coll Cardiol 2005;46:2277-83.

19. Janousek J, Gebauer RA, Abdul-Khaliq H, et al. Cardiac resynchronisation therapy in paediatric and congenital heart disease: differential effects in various anatomical and functional substrates. Heart 2009;95:1165-71.

20. Cecchin F, Frangini PA, Brown DW, et al. Cardiac resynchronization therapy (and multisite pacing) in

Cite this article as: Ellenberger K, Negishi K. Subclinical myocardial dysfunction and dyssynchrony after Ross or RossKonno procedure. Transl Pediatr 2020;9(2):191-194. doi: 10.21037/tp.2020.03.11 pediatrics and congenital heart disease: Five years experience in a single institution. J Cardiovasc Electrophysiol 2009;20:58-65.

21. Mollema SA, Bleeker GB, van der Wall EE, et al. Usefulness of QRS Duration to Predict Response to Cardiac Resynchronization Therapy in Patients With End-Stage Heart Failure. Am J Cardiol 2007;100:1665-70.

22. Bansal N, Kumar SR, Baker CJ, et al. Age-related outcomes of the Ross procedure over 20 years. Ann Thorac Surg 2015;99:2077-83; discussion 2084-5.

23. Kwok SY, Yeung SS, Li VW, et al. Ventricular mechanics after repair of subarterial and perimembranous VSDs. Eur J Clin Invest 2017. doi: 10.1111/eci.12852.

24. Grotenhuis HB, Cifra B, Mertens LL, et al. Left ventricular remodelling in long-term survivors after the arterial switch operation for transposition of the great arteries. Eur Heart J Cardiovasc Imaging 2019;20:101-7. 